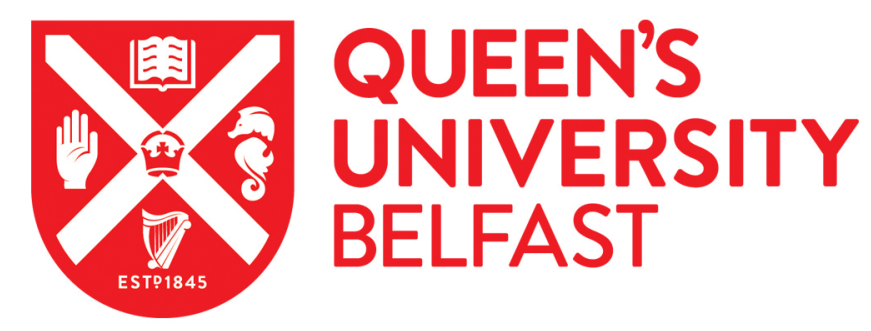

\title{
Effects of Paenibacillus polymyxa inoculation on below-ground nematode communities and plant growth
}

Finch, E. A., Caruso, T., \& Engl, C. (2018). Effects of Paenibacillus polymyxa inoculation on below-ground nematode communities and plant growth. Soil Biology and Biochemistry, 121, 1-7.

https://doi.org/10.1016/j.soilbio.2018.01.026

Published in:

Soil Biology and Biochemistry

Document Version:

Peer reviewed version

Queen's University Belfast - Research Portal:

Link to publication record in Queen's University Belfast Research Portal

Publisher rights

(C) 2018 Elsevier Ltd. All rights reserved.

This manuscript version is made available under the CC-BY-NC-ND 4.0 license http://creativecommons.org/licenses/by-nc-nd/4.0/,which permits distribution and reproduction for noncommercial purposes, provided the author and source are cited.

\section{General rights}

Copyright for the publications made accessible via the Queen's University Belfast Research Portal is retained by the author(s) and / or other copyright owners and it is a condition of accessing these publications that users recognise and abide by the legal requirements associated with these rights.

Take down policy

The Research Portal is Queen's institutional repository that provides access to Queen's research output. Every effort has been made to ensure that content in the Research Portal does not infringe any person's rights, or applicable UK laws. If you discover content in the Research Portal that you believe breaches copyright or violates any law, please contact openaccess@qub.ac.uk. 
1 Effects of Paenibacillus polymyxa inoculation on below-ground nematode communities 2 and plant growth.

3 Elizabeth A Finch ${ }^{1}$, Tancredi Caruso ${ }^{1 *}$ and Christoph Engl ${ }^{1,2^{*}}$

$4{ }^{1}$ School of Biological Sciences and Institute of Global Food Security, Queen's University 5 Belfast, Medical Biology Centre, 97 Lisburn Road, Belfast BT9 7BL, Northern Ireland, UK.

$6 \quad{ }^{2}$ School of Biological and Chemical Sciences, Queen Mary University of London, E1 4NS, UK.

$7 \quad$ * to whom correspondence should be addressed:

$8 \quad$ Christoph Engl: c.engl@qmul.ac.uk; Tel: + 44 (0) 2078823315

$9 \quad$ Tancredi Caruso: t.caruso@qub.ac.uk; Tel: + 44 (0) 2890972271

10 Word count: 4140

11 Figures in total: 4

12 Figures produced in colour: 3 (Figure 1, 3 and 4) 
Abstract

Paenibacillus polymyxa has been shown to have great potential as a bio-fertiliser and biocontrol agent, however information regarding its effect on below-ground biota when used as a soil additive is scarce. Below-ground biota provide vital services to boost plant performance and thus knowledge regarding their response to bio-fertiliser and biocontrol agents is critical for future crop management.

Here, we extracted below-ground nematode (N) and microbial communities (M) and reassembled them in presence and absence of $P$. polymyxa soil inoculation $(\mathrm{P})$. We then assessed the impacts of each of the three components, individually and in combination, on nematode community structure and plant growth.

The main pattern was a gradual shift in the below-ground nematode community from those with increased abundances of omnivorous and plant parasitic nematodes towards those with increased abundances of predatory nematodes along the treatment gradient from N, to N,M to N,P to N,M,P. This shift from increased abundances of omnivores and plant parasitic nematodes to increased abundances of predatory nematodes was significantly positively correlated with plant growth.

In conclusion, our study demonstrates for the first time that inoculation of soil with P. polymyxa changes the below-ground nematode community resulting in significant changes to plant growth.

\section{Highlights}

- Non-inoculated communities associated with omnivore and plant parasitic nematodes.

- P. polymyxa acts with soil microflora to increase predatory nematode abundance.

- Plant growth correlated with a shift in nematode community composition.

- Increased abundance of plant parasitic nematode linked to reduced plant growth.

- Increased abundance of predatory nematode linked to increased plant growth.

\section{Introduction}

Meeting the increasing demand for food caused by global population and economic growth is one of the major challenges of the $21^{\text {st }}$ century (FAO, 2012). It is predicted that maintaining global food security will require a doubling of agricultural outputs (Tubiello et al., 2007; FAO, 2012) and a shift towards the use of more sustainable and eco-friendly bio-fertiliser and 
biocontrol agents made from plant beneficial microbes. One determinant for plant growth is the intricate interplay between plants and the below-ground biota (van der Heijden et al., 2008; Ferris et al., 2012). It is therefore critical to understand the effect of plant beneficial microbes, when applied as soil inoculum, on below-ground biota. Paenibacillus polymyxa is a plant beneficial soil bacterium, that shows great potential for development as a bio-fertiliser and biocontrol agent due to its plant growth promoting traits including nitrogen fixation, phosphorus solubilisation, production of phytohormones and protection against plant pathogens (Lal \& Tabacchioni, 2009; Eastman et al., 2014; Grady et al., 2016). Yet information regarding its impact on the below-ground biota and associated processes is scarce.

Nematodes are an abundant and diverse below-ground metazoan community (Bernard, 1992). They provide significant ecosystem services and as such serve as useful indicators for soil quality (Neher, 2001). To date, the impact of $P$. polymyxa on nematodes has only been studied in artificial binary interactions involving a single trophic nematode group where it was observed to have nematicidal activity against plant parasitic nematodes and thereby suppresses plant diseases such as root galling and wilting (Khan et al., 2008; Son et al., 2009). Belowground nematode communities however, are comprised of 5 different trophic groups: i) bacterivores; ii) fungivores; iii) plant parasitic nematodes; iv) predators; v) omnivores (Yeates et al., 1993; Bonger \& Bongers, 1998). Combined they play important roles below ground e.g. they contribute to nutrient cycling through the mineralisation of nitrogen, they distribute microbes through the soil, they serve as food source for other soil dwelling organisms, and they both contribute to and antagonise plant diseases (Ferris et al., 2012). They also interact with the microbial community within the soil. These interactions can be beneficial to the microbial community, for example root infestation by plant parasitic nematodes can lead to 'leakage' of nutrients from damaged plant root systems which results in an enhanced microbial biomass (Yeates et al., 1998) or detrimental, for example bacterivorous nematode activity can lead to a significant decrease in microbial biomass (Bardgett et al., 1999). However, little is known about how the different nematode trophic groups interact and we lack any information on how they are affected by P. polymyxa.

In this study we conducted a factorial experiment in controlled conditions which allowed us to assess changes to the below-ground nematode community structure and the resulting effect on plant growth in response to i) the native below-ground microbial community, and to ii) inoculation by P. polymyxa. We hypothesised, based on the outcomes of previous binary 
interaction studies (Khan et al., 2008; Son et al., 2009), that $P$. polymyxa would reduce the abundance of plant parasitic nematodes leading to further changes within the below-ground nematode community. We further hypothesised that this reduction in plant parasitic nematodes would have a beneficial effect on plant growth.

\section{Material and Methods}

\subsection{Extraction of nematodes and soil microbial communities.}

Nematodes were extracted from $5.2 \mathrm{~kg}$ of multipurpose compost using a modification of Cobb's decanting and sieving method (Van Bezooijen, 2006) followed by the Baermann funnel methods (Barker, 1985). To remove large particles, soil was washed through a $4 \mathrm{~mm}$ aperture sieve. The remaining soil suspension was then stirred vigorously, left to settle for $15 \mathrm{~s}$ and then passed through a $250 \mu \mathrm{m}$ sieve, followed by a $53 \mu \mathrm{m}$ sieve. The contents of these sieves were then washed into a nematode extraction container lined with a $20 \mathrm{~cm}$ Easy Flow Bonded Fibre Milk Filter (GD Textile). This was attached to a glass vial at the bottom for the eventual collection of nematodes (nematode wash). Samples were left for $24 \mathrm{~h}$ at $23^{\circ} \mathrm{C}$. The remaining soil suspension was passed through a $35 \mu \mathrm{m}$ sieve in order to collect the microbial community (microbial wash). The contents of this sieve were washed into test tubes with water. Both the nematode and the microbial extractions were then divided into 4 equal measures for the resulting treatments.

\subsection{Sterilisation of seeds and seedling preparation}

Arabidopsis thaliana Col-0 seeds were sterilised by immersion in 70\% ethanol followed by $50 \%$ bleach solution for 10 minutes and then rinsed twice with autoclaved $\mathrm{dd}_{2} \mathrm{O}$. Sterilised seeds were germinated on a solid 1/2x Murashige and Skoog medium (Sigma M5524) supplemented with $1.5 \%$ agar. For vernalisation, the seeds were incubated at $4^{\circ} \mathrm{C}$ for 2 days before growth at $25^{\circ} \mathrm{C}$ with $80 \%$ relative humidity and a photoperiod of $16 \mathrm{~h}$ light / $8 \mathrm{~h}$ dark. After 4 days, seedlings were potted into soil, see Soil treatment.

\subsection{Preparation of the Paenibacillus polymyxa inoculum}

Paenibacillus polymyxa strain ATCC 842 (Bacillus Genetic Stock Center) was grown in SOC medium at $30^{\circ} \mathrm{C}$ overnight with shaking. The overnight culture was washed twice with Ringer's solution and adjusted to $10^{5}$ colony forming units before being used as soil inoculum, see Soil treatment. 


\subsection{Soil treatment}

108

109

110

111

112

113

114

115

116

117

118

119

120

121

122

123

124

125

126

127

128

129

130

131

132

133

134

135

136

137

Multipurpose compost was autoclaved in small batches and a subsample was checked for the presence of nematodes. The nematode free autoclaved compost was then potted into 56 pots ( $140 \mathrm{~g}$ per pot). These pots were subjected to the following treatments: $\mathrm{C}=$ control (autoclaved soil); $\mathrm{M}=$ below-ground microbial community only; $\mathrm{P}=\mathrm{P}$. polymyxa only; $\mathrm{M}, \mathrm{P}$ $=$ below-ground microbial community and $P$. polymyxa $; \mathrm{N}=$ below-ground nematode community only; N,M = below-ground nematode and microbial communities; N,P = belowground nematode communities and $P$. polymyxa; N,P,M = below-ground nematode and microbial communities and P. polymyxa. N,M hereby represents the most natural condition since both $\mathrm{N}$ and $\mathrm{M}$ were extracted directly from the soil, while in contrast $\mathrm{P}$ was used as external inoculum. Moreover, all individual components originated from the same pool of either N, M, or P respectively, enabling us to directly compare treatments. As defined by the treatment, in addition to Arabidopsis thaliana Col-0 seedlings, each pot received $6 \mathrm{~mL}$ of nematode wash, $6 \mathrm{~mL}$ of microbial wash, $6 \mathrm{~mL}$ of $10^{5}$ Paenibacillus polymyxa in ringers solution, $6 \mathrm{~mL}$ of water (as a control for $\mathrm{N}$ and $\mathrm{M}$ ) or $6 \mathrm{~mL}$ of ringers solution (as a control for P). All treatments had 7 replicates except $\mathrm{N}$ and N,P which both had 6 replicates. The pots were then incubated in a growth chamber at $25^{\circ} \mathrm{C}$ with $80 \%$ relative humidity and a photoperiod of $16 \mathrm{~h}$ light / $8 \mathrm{~h}$ dark. Pots were watered daily to field capacity. After one week, we removed all the seedlings and quantified plant growth using plant height which we measured as the height of each seedling from the bottom of the stem to the top of the main plant stem.

Where nematodes were added, we extracted the nematodes using the method detailed above. Each nematode extraction was diluted to $20 \mathrm{~mL}$. The extraction was then mixed thoroughly and $1 \mathrm{~mL}$ was placed onto a $1 \mathrm{~mL}$ cytometer slide. Nematodes were counted and identified using a Leica M165 C stereo-microscope (Leica Microsystems, Heerbrugg, Switzerland). Identification of the different trophic groups was carried out by observing mouth structure and movement behaviour (Dindal, 1990; Yeates et al., 1993). Using the total nematode count from the $1 \mathrm{~mL}$ subsample, we scaled up to obtain the total nematode count for $20 \mathrm{~mL}$. Nematode trophic group frequencies were recorded and a total for the whole nematode extraction $(20 \mathrm{~mL})$ was calculated.

\subsection{Analysis methods}




\subsubsection{Nematode trophic group abundance}

139 We used a generalised least-squares approach to test for difference in the abundances of each

140 trophic group between all treatments and the nematode only treatment. Each treatment was categorised using two factors: whether or not below-ground microbial communities were added, and whether or not $P$. polymyxa inoculum was added. We included both factors, as well as the interaction between them, into the model as fixed effects. We also accounted for heterogeneity of variances within the models using the varIdent function (Zuur et al., 2009).

\subsubsection{Plant growth}

We used linear models to look for difference in plant growth between a) the control group b) the nematode treatment, and c) all the other treatments. Each treatment was categorised using two factors: whether or not below-ground microbial communities, nematodes or both belowground microbial and nematode communities were added, and whether or not $P$. polymyxa was added. We included both factors, as well as the interaction between them, into the model as fixed effects. As a post-hoc test, we used a Tukey's honest significant difference to test for differences in plant growth between the treatments. Additionally, we correlated the axis one and axis two loadings from the PCoA with plant growth using Pearson's moment correlation tests.

\subsubsection{Nematode community composition}

156 We used a Hellinger transformation on the nematode trophic group abundance data to allow 157 Euclidean-based ordination methods to be used. Hellinger transformations are recommended 158 because they do not strongly weight rare species in the analysis (Legendre \& Gallagher, 2001). 159 We then used Principal Coordinates Analysis (PCoA) to summarise the effect of the different 160 treatments on the nematode trophic group composition. We extracted the axis one and axis two loadings for each assay for further analysis.

162 We carried out these analyses using $\mathrm{R}$ version 3.2.2 ( $\mathrm{R}$ Development Core Team 2016: 163 http://www.rproject.org), nlme (Pinheiro et al., 2016), vegan (Oksanen et al., 2006) and using packages ggplot2 (Wickham, 2009) and wesanderson (Ram \& Wickham, 2016) for graphical display.

\section{Results}




\subsection{Nematode community composition}

168 The first axis of the PCoA accounted for $43 \%$ of the total variation and showed a gradient from 169 fungivores on the negative side, to bacterivores on the positive side of the axis (Fig. 1a). 170 Average loadings for axis one for each of the treatments also reflected this gradient: we observed that $\mathrm{N}$ was more associated with fungivores as shown by the negative average loadings. However, the loadings became increasingly more positive (and thus more associated with bacterivores) from $\mathrm{N}$ to N,M to N,P to N,M,P (Fig. 1b).

The second axis of the PCoA accounted for $33 \%$ of the total variation and showed a gradient from fungivores, plant parasitic nematodes, omnivores, and bacterivores on the positive side, to predatory nematodes on the negative side of the axis (Fig. 1a). Average axis two loadings for each treatment showed that $\mathrm{N}$ was more associated with all nematode trophic groups (except predatory nematodes), but that along the gradient from the $\mathrm{N}$ to $\mathrm{N}, \mathrm{M}$ to $\mathrm{N}, \mathrm{P}$ to $\mathrm{N}, \mathrm{M}, \mathrm{P}$ the treatments become increasingly associated with predatory nematodes (Fig. 1c).

\subsection{Nematode trophic group abundance}

We found that there was a significant increase in the number of predatory nematodes in N,M,P compared to N (Fig. 2e: Supporting information Table S1). However, separately, neither M nor $\mathrm{P}$ had a significant effect on predatory nematodes (Supporting information Table S1). Additionally, there was no significant effect of $\mathrm{M}$ and $\mathrm{P}$ separately or the interaction between the two on any of the other nematode trophic groups (Supporting information Table S1). However, we note that along the gradient of treatments from $\mathrm{N}$ to N,M to N,P to N,M,P there was a trend towards decreasing abundances of omnivores (Fig. 2c) and plant parasitic nematodes (Fig. 2d).

\subsection{Plant growth}

Below-ground biota (nematode and microbial communities) had a significant positive effect on plant growth $\left(\mathrm{F}_{3,46}=6.65 ; \mathrm{p}<0.001\right)$ as did the interaction between the below-ground biota and the added $P$. polymyxa $\left(\mathrm{F}_{3,46}=3.02 ; \mathrm{p}<0.05\right)$. A posthoc tukey test showed that compared to the control treatment, plant growth was significantly increased with N,P and N,M,P (Supporting information Table S2) (Fig. 3a). 
When we correlated axis loadings from the PCoA of nematode community composition, we found that axis one loadings, which represented a gradient from fungivores to bacterivores, was not significantly correlated with either plant growth (Fig. 3b). However, axis two loadings which represented a gradient from fungivores, plant parasitic nematodes, omnivores, and bacterivores to predatory nematodes, was significantly correlated with plant growth $\left(\mathrm{r}_{24}=-0.47\right.$, $\mathrm{p}=0.02)($ Fig.3c).

\section{Discussion}

In this study we conducted a factorial experiment in controlled conditions which allowed us to assess, both individually and in combination, the impact of microbial $(\mathrm{M})$ and nematode $(\mathrm{N})$ communities, as well as the application of an external bacterial bio-fertiliser, $P$. polymyxa (P) on plant growth and nematode community structure.

\subsection{Arabidopsis plant growth in presence of native below-ground biota represents an intermediate between the individual constituent parts}

It has been reported that nematodes can have different effects on plant performance; bacterivores, fungivores and omnivores can improve plant performance through indirect nutrient release as when feeding on microbes they excrete excess nutrients which can then be taken up by plants (Ingham et al., 1985; Bonkowski et al., 2000; Osler \& Sommerkorn, 2007; Gebremikael et al., 2016). Plant parasitic nematodes, however, have been shown to decrease plant production, and disrupt plant nutrient and water transfer (Yeates \& Coleman, 1982; Brussaard et al., 1997). Predatory nematodes may have a dual function - i) they have the potential to act as a biocontrol for plant parasitic nematodes (Khan \& Kim, 2007), and ii) they stimulate cycling of plant nutrients, potentially enabling plants to withstand any nematode burden on their roots (Yeates \& Wardle, 1996). We observed no increase in plant growth, compared to the sterile control when only nematodes $(\mathrm{N})$ were present. These below-ground nematode communities comprised of bacterivores, fungivores, omnivores and plant parasitic nematodes but lacked high abundances of predators. Given that the positive effect of bacterivores, omnivores and fungivores is dependent on the presence of microbial prey, the lack of a microbial community in the $\mathrm{N}$ treatment may explain why under this condition plants showed no increase in plant growth compared to the control. Consistent with this, we observed an increase in plant growth compared to the control when plants had most natural conditions i.e. when they were treated with a combination of below-ground nematode and microbial 
communities $(\mathrm{N}, \mathrm{M})$. The microbial community inoculum was created by sieving soil using a 35um sieve. A previous study by Wagg et al., (2014) suggests that the use of this size sieve will exclude some of the microbial community. However, given that identical methods were used to create all the microbial community inoculums and the comparative nature of this study, we suggest that this does not affect our results. Further work, on the effect of P. polymyxa should include in situ experiments.

\subsection{Plant growth and native nematode community in response to $P$. polymyxa inoculation}

Inoculation by $P$. polymyxa $(\mathrm{P})$ in absence of $\mathrm{M}$ and $\mathrm{N}$ had no significant effect on plant growth compared to sterile soil (C). Previous studies suggest that plant growth promotion by $P$. polymyxa may be context dependent e.g. Timmusk \& Wagner (1999) reported that plants inoculated by $P$. polymyxa had a $30 \%$ reduction in growth, a stunted root system, and an increased expression of plant stress response genes. This suggests that $P$. polymyxa can act as a mild biotic stress (Timmusk \& Wagner, 1999).

Remarkably, compared to P. polymyxa alone (P), the below-ground nematode community alone $(\mathrm{N})$ and the sterile soil (C), P. polymyxa shows a significant positive effect on plant growth when in synergy with the below-ground nematode community (N,P) and with both the below-ground nematode and microbial community together (N,M,P). Furthermore, the belowground nematode community gradually shifts towards increasing dominance by bacterivores along the treatment gradient from $\mathrm{N}$ to $\mathrm{N}, \mathrm{M}$ to N,P to N,M,P indicating an additive effect of $\mathrm{M}$ and P. This shift, however, is not directly due to a significant increase in the abundance of bacterivores, but rather as an indirect result of a decrease in the number of fungivores, omnivores and plant parasitic nematodes. Moreover, our data suggests that increased dominance by bacterivores is not the basis of the positive effect on plant growth observed in N,P and N,M,P. Conversely, there was a significant correlation between plant growth and the shift along the same treatment gradient towards communities increasingly associated with predatory nematodes (Fig.4). Predatory nematodes feed on bacterivores, fungivores, omnivores and plant parasitic nematodes (Yeates et al., 1993; Bonger \& Bongers, 1998). Interestingly, whilst we see below-ground nematode communities increasingly associated with predators along the treatment gradient from $\mathrm{N}$ to $\mathrm{N}, \mathrm{M}$ to $\mathrm{N}, \mathrm{P}$ to $\mathrm{N}, \mathrm{M}, \mathrm{P}$, at the polar end of this gradient we observe communities which have higher proportions of omnivores and plant parasitic nematodes. We therefore suggest that the omnivores and plant parasitic nematodes may act as 
have shown that $P$. polymyxa reduces the vitality of the plant parasitic nematode Meloidogyne incognita suggesting that in our study $P$. polymyxa might weaken plant parasitic nematodes and facilitate their predation by predatory nematodes which in turn may result in improved plant performance. The interplay between omnivores, plant parasitic nematodes and predators upon $P$. polymyxa inoculation are subject to ongoing investigations.

Notably, the frequent cultivation of agricultural soils results in the depletion of predatory nematodes with an associated loss of soil suppressiveness against plant parasitic nematodes (Ferris et al., 2012). One way to mitigate this negative effect is the use of conservation tillage, this process however takes more than 2 years (Ferris et al., 2012). Our study suggests that application of $P$. polymyxa as a soil additive may be an additionally faster strategy to increase predatory nematodes in agroecosystems.

\subsection{Conclusions}

Our study for the first time demonstrates that $P$. polymyxa changes the below-ground nematode community by increasing the dominance of predatory nematodes. We therefore conclude that in addition to the reported direct protection of plants by inhibiting plant pathogens through the production of antibiotic compounds, $P$. polymyxa may also indirectly protect plants by increasing other soil dwelling organisms such as predatory nematodes which themselves have biocontrol characteristics.

\section{Acknowledgements}

We would like to thank Mr Christopher Cregan for technical support. This project was funded by a Queen's University Research Fellowship to CE and by the grant SENSE (Structure and Ecological Niche in the Soil Environment; EC FP7 - 631399 - SENSE) to TC.

\section{References}

Bardgett, R.D., Cook, R., Yeates, G.W., Denton, C.S., 1999. The influence of nematodes on below-ground processes in grassland ecosystems. Plant and Soil, 212, 23-33.

Barker, K.R., 1985. Nematode extraction and bioassays. In: Barker KR, Carter CC, Sasser JN, eds. An Advanced Treatise on Meloidogyne, Methodology, vol. 2. North Carolina State University Graphics. 
287

288

289

290

291

292

293

294

295

296

297

298

299

300

301

302

303

304

305

306

307

308

309

310

311

Bongers, T., Bongers, M., 1998. Functional diversity of nematodes. Applied Soil Ecology, 10, 239-251.

Bonkowski, M., Cheng, W.X., Griffiths, B.S., Alphei, G., Scheu, S., 2000. Microbial-faunal interactions in the rhizosphere and effects on plant growth. European Journal of Soil Biology, $36,135-147$.

Brussaard, L.V., Behan-Pelletier, M., Bignell, D.E., Brown, V.K., Didden, W., Folgarait, P., Fragoso, C., Freckman, D.W., Gupta, V.V.S.R., Hattori, T., Hawksworth, D.L., Klopatek, C., Lavelle, P., Malloch, D.W., Rusek, J., Söderström, B., Tiedje, J.M., Virginia, R.A., 1997. Biodiversity and ecosystem functioning in soil. Ambio, 26, 563-570.

Chen, S.Y., Dickson, D.W., Mitchell, D.J., 1995. Effects of Soil Treatments on The Survival of Soil Microorganisms. The Journal of Nematology, 27, 661-663.

Dindal, D.L. 1990. Soil biology guide. New York: John Wiley \& Sons; Chapter 8.

Eastman, A.W., Heinrichs, D.E., Ze-Chun, Y., 2014. Comparative and genetic analysis of the four sequenced Paenibacillus polymyxa genomes reveals a diverse metabolism and conservation of genes relevant to plant-growth promotion and competitiveness. BMC Genomics, 15, 851.

FAO, WFP and IFAD. 2012. The State of Food Insecurity in the World 2012. Economic growth is necessary but not sufficient to accelerate reduction of hunger and malnutrition. Rome, FAO.

Ferris, H., Griffiths, B.S., Porazinska, D.L., Powers, T.O., Wang, K-H., Tenuta, M., 2012. Reflections on Plant and Soil Nematode Ecology: Past, Present and Future. Journal of Nematology, 44, 115-126.

Gebremikael, M.T., Steel, H., Buchan, D., Bert, W., De Neve, S., 2016. Nematodes enhance plant growth and nutrient uptake under C and N-rich conditions. Scientific Reports, 6, 32862

Grady, E.N., MacDonald, J., Liu, L., Richman, A., Yuan, Z.C., 2016. Current knowledge and perspectives of Paenibacillus: a review. Microbial Cell Factories, 15, 203 
312 Ingham, R.E., Trofymow, J.A., Ingham, A., Coleman, D.C., 1985. Interactions of bacteria, 313 fungi, and their nematode grazers: effects on nutrient cycling and plant growth. Ecological 314 Monographs, 55, 119-140.

315 Khan, Z., Kim, Y.H., 2007. A review on the role of predatory soil nematodes in the biological 316 control of plant parasitic nematodes. Applied Soil Ecology, 35, 370-379.

317 Khan, Z., Kim, S.G., Jeon, Y.H., Khan, H.U., Son, S.H., Kim, Y.H., 2008. A plant growth 318 promoting rhizobacterium, Paenibacillus polymyxa strain GBR-1, suppresses root-knot nematode. Bioresource Technology, 99, 3016-3023.

Lal, S., Tabacchioni, S., 2009. Ecology and biotechnological potential of Paenibacillus polymyxa: a minireview. Indian Journal of Microbiology, 49, 2-10

Legendre, P., Gallagher, E.D., 2001. Ecologically meaningful transformations for ordination of species data. Oecologia, 129, 271-280.

Neher, D.A., 2001. Role of nematodes in soil health and their use as indicators. Journal of Nematology, 33, 161-168.

326 Oksanen, J., Kindt, R., Legendre, P., O’Hara, R.B., 2006. Vegan: Community Ecology Package version $1.8-2$.

Osler, G.H.R., Sommerkorn, M., 2007. Toward a complete soil C and N cycle: incorporating the soil fauna. Ecology, 88, 1611-1621.

330 Pinheiro, J., Bates, D., DebRoy, S., Sarkar, D., R Core Team. 2016. nlme: Linear and Nonlinear 331 Mixed Effects Models. R package version 3.1-123

332 R Core Team. 2016. R: A language and environment for statistical computing. R Foundation 333 for Statistical Computing, Vienna, Austria. URL https://www.R-project.org/. 
Son, S.H., Khan, Z., Kim, S.G., Kim, Y.H., 2009. Plant growth-promoting rhizobacteria, Paenibacillus polymyxa and Paenibacillus lentimorbus suppress disease complex caused by root-knot nematode and fusarium wilt fungus. Journal of Applied Microbiology, 107, 524-532.

Timmusk, S., Wagner, E.G., 1999. The Plant-Growth-Promoting Rhizobacterium Paenibacillus polymyxa induces changes in Arabidopsis thaliana gene expression: a possible connection between biotic and abiotic stress responses. Molecular Plant-Microbe Interactions, $12,951-959$.

Tubiello, F.N., Soussana, J-F., Howden, S.M., 2007. Crop and pasture response to climate change. Proceedings of the National Academy of Sciences of the United States of America, 104, 19686-19690.

Van Bezooijen, J., 2006. Methods and Techniques for Nematology. Wageningen, Netherlands: Wageningen University.

van der Heijden, M.G., Bardgett, R.D., van Straalen, N.M., 2008. The unseen majority: soil microbes as drivers of plant diversity and productivity in terrestrial ecosystems. Ecology Letters, 11, 296-310

Wagg, C., Bender, S.F., Widmer, F., van der Heijden, M.G.A., 2014. Soil biodiversity and soil community composition determine ecosystem multifunctionality. Proceedings of the National Academy of Sciences, USA, 111, 5266-5270.

Wickham, H. 2009. ggplot2: Elegant Graphics for Data Analysis. Springer-Verlag New York, Yeates, G.W., Coleman, D.C., 1982. Nematodes in decomposition. In Freckman, DW, eds. Nematodes in soil ecosystems. Austin, TX: University of Texas.

Yeates, G.W., Bongers, T., De Goede, R.G.M., Freckman, D.W., Georgieva, S.S., 1993. Feeding Habits in Soil Nematode Families and Genera-An Outline for Soil Ecologists. Journal of Nematology, 25, 315-331

Yeates, G.W., Wardle, D.A., 1996. Nematodes as predators and prey: relationships to biological control and soil processes. Pedobiologia, 40, 43-50. 
361 Yeates, G.W., Saggar, S., Denton, C.S., Mercer, C.F., 1998. Impact of clover cyst nematode 362 (Heterodera trifolii) infection on soil microbial activity in the rhizosphere of white clover 363 (Trifolium repens) - a pulse labelling experiment. Nematologica. 44, 81-90. and extensions in ecology with R. New York: Springer.

Supplementary materials:

367 Generalised least squares model output for the effect of treatment on predatory nematode 368 abundance (Table S1); Analysis results for testing the effect of treatment on plant growth 369 (Table S2).

Key words:

371

Arabidopsis thaliana; below-ground communities; bio-fertiliser and biocontrol agent; nematode; Paenibacillus polymyxa; plant growth promotion; plant - soil biota interaction; soil ecology.

\section{Figure legends:}

Figure 1. Effects of the native microbial community and Paenibacillus polymyxa inoculation on below-ground nematode community composition. a) Ordination plots of the Principal Coordinate Analysis on the nematode trophic group abundance as dependent on treatment type. Each line on the diagram represents a site for the corresponding habitat while label in boxes are the habitat centroids. $\mathrm{N}$ = below-ground nematode only treatment (blue lines); $\mathrm{N}, \mathrm{M}=$ treatment with below-ground nematode and microbial communities (green lines); $\mathrm{N}, \mathrm{P}=$ below-ground nematode communities and $P$. polymyxa treatment (red lines); N,P,M = treatment with below-ground nematode and microbial communities and P. polymyxa (yellow lines). Also shown are the nematode trophic groups: Fungi $=$ fungivores, Plant $=$ plant parasitic nematodes, Omni $=$ omnivores, Bact $=$ bacterivores, Pred $=$ predatory nematodes. b) Mean loadings for axis one of the PCoA for each treatment with standard error c) Mean loadings for axis two of the PCoA for each treatment with standard error.

Figure 2. Effects of the native microbial community and Paenibacillus polymyxa inoculation on abundances of trophic groups within below-ground nematode communities. Shown are mean abundances for a) bacterivores, b) fungivores, c) omnivores, 
d) plant parasitic nematodes, e) predatory nematodes for each treatment with standard errors. Bars with different letters are significantly different.

Figure 3. Plant growth as measured by plant height in response to below-ground nematode and microbial communities as well as Paenibacillus polymyxa inoculation. a)

Mean plant height for all the different treatment types with standard errors are shown. Bars with different letters show those treatments which were significantly different from the control treatment. $\mathrm{C}=$ control; $\mathrm{M}=$ below-ground microbial community treatment only; $\mathrm{P}=P$. polymyxa treatment only; M,P = below-ground microbial community and $P$. polymyxa treatment; $\mathrm{N}=$ below-ground nematode community only treatment; $\mathrm{N}, \mathrm{M}=$ treatment with below-ground nematode and microbial communities; N,P = treatment with below-ground nematode communities and $P$. polymyxa; $\mathrm{N}, \mathrm{P}, \mathrm{M}=$ treatment with below-ground nematode and microbial communities and P. polymyxa. Correlations between the loadings of $b$ ) axis ones and c) axis two of the PCoA, and plant height. Each circle represents one assay. Blue dots $=\mathrm{N}$; Green dots $=$ N,M; Red dots $=$ N,P; Orange dots $=$ N,M,P.

Figure 4. Effect of Paenibacillus polymyxa on the nematode food web in soil. Solid line arrows indicate feeding connections within the food web, with arrow direction depicted from food source towards consumer. The red arrows indicate the proposed effect of Paenibacillus polymyxa on plant growth via direct and indirect interactions with plant parasitic nematodes and predatory nematodes. The size of the nematodes corresponds to the abundances measured in this study. Paenibacillus polymyxa inoculation results in a decrease in the abundance of omnivorous and plant parasitic nematodes and an increase in the abundance of predatory nematodes while abundances of fungi- and bacterial-feeding nematodes are unaffected. These changes in the nematode food web correlate with an increase in plant growth in response to soil inoculation with Paenibacillus polymyxa which we propose, based on Khan et al., (2008) and Son et al., (2009), occurs as a result of Paenibacillus polymyxa weakening plant parasitic nematodes (as represented by the red dashed line) and facilitating their predation by predatory nematodes (as represented by the thick red line), which in turn reduces the negative effects of plant parasitic nematodes on the plants (as represented by the thin red line). 
Figure 1

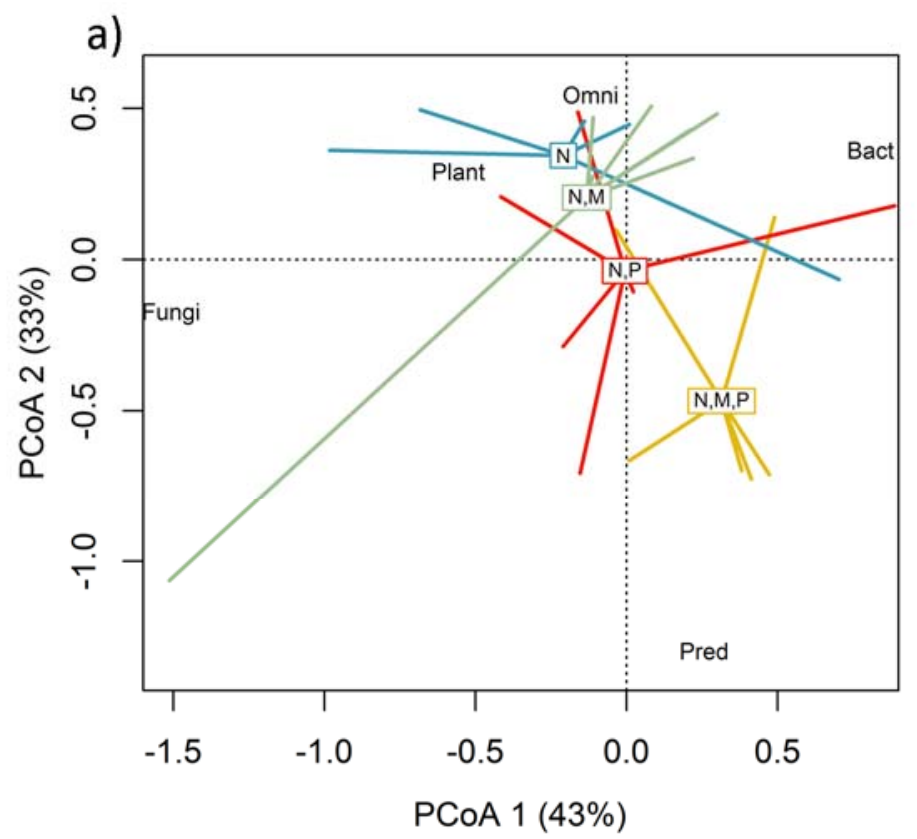

b)

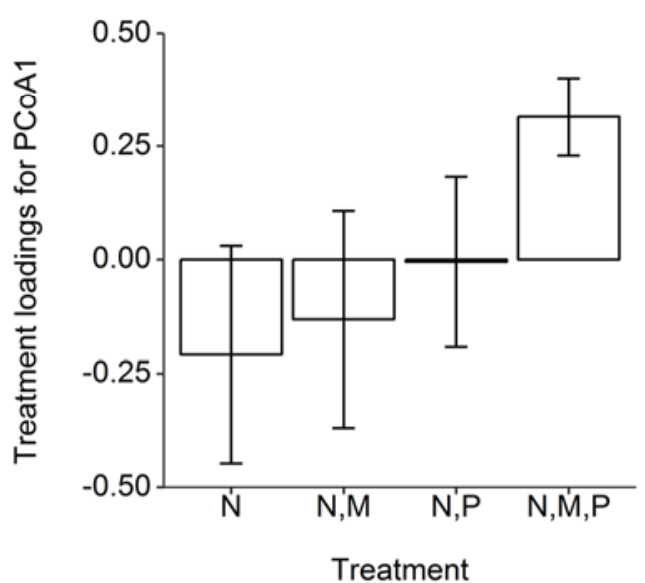

c)

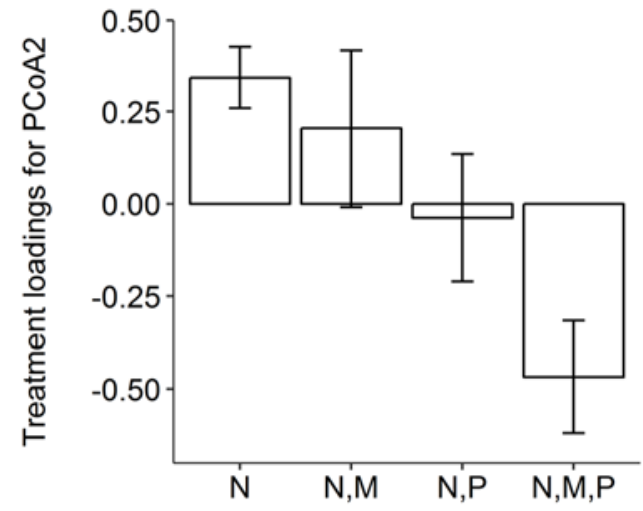

Treatment 
Figure 2
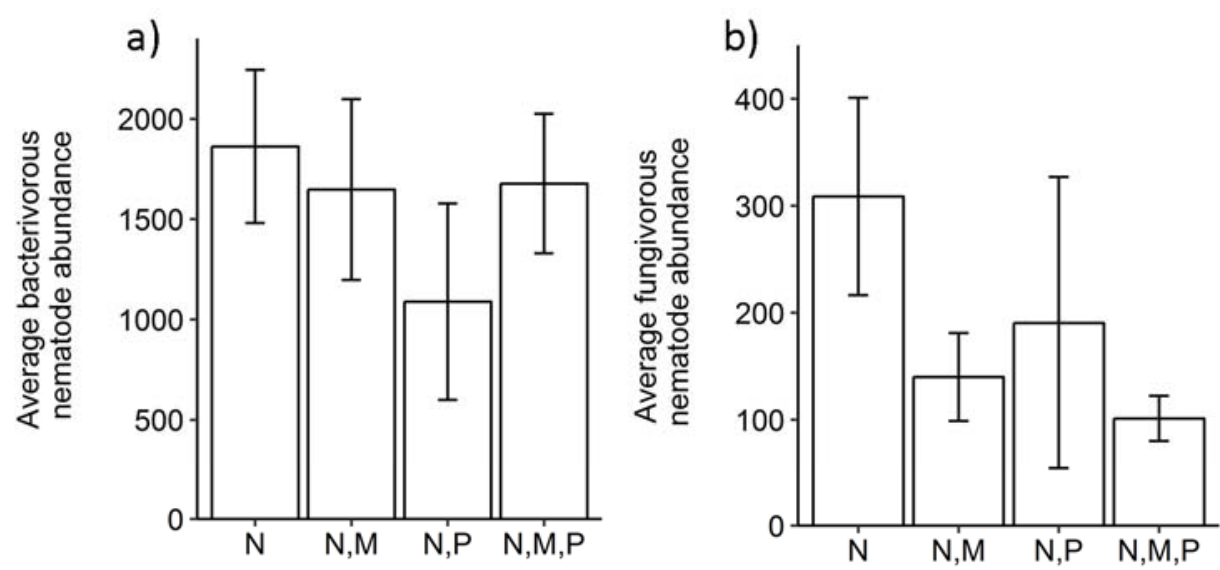

c)

Treatment

d)

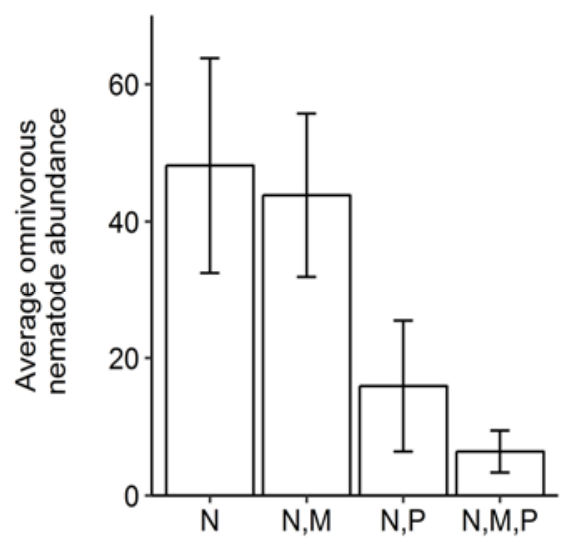

e)

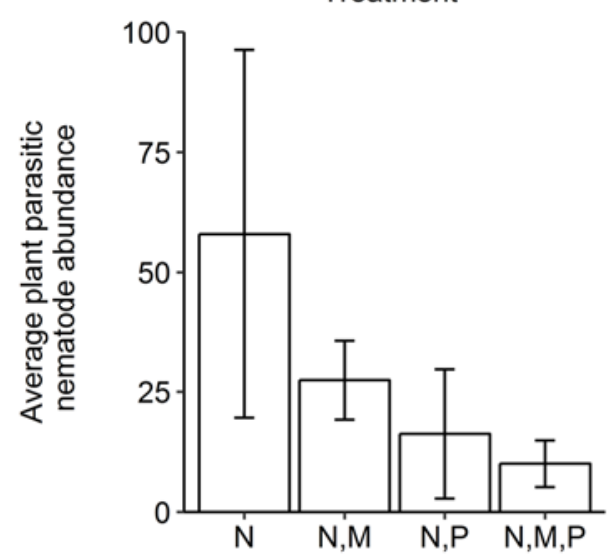

Treatment

Treatment

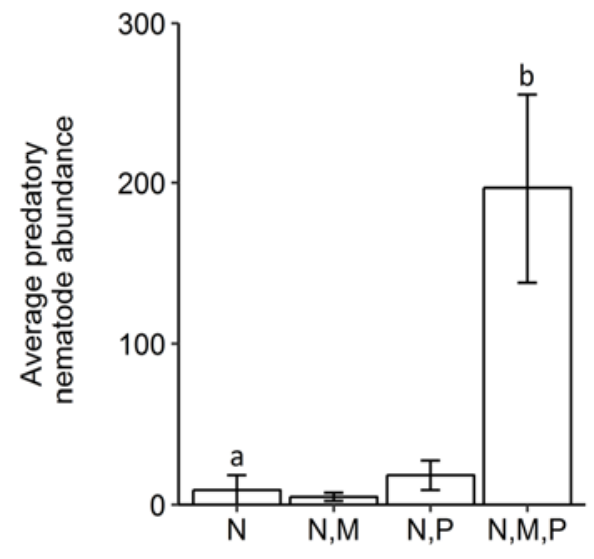

428

Treatment

429

430

431 
432

433

434

435

436

437

438

439

440

441

442

443

444

445

446

447

448

449

450

451

452

453 a)

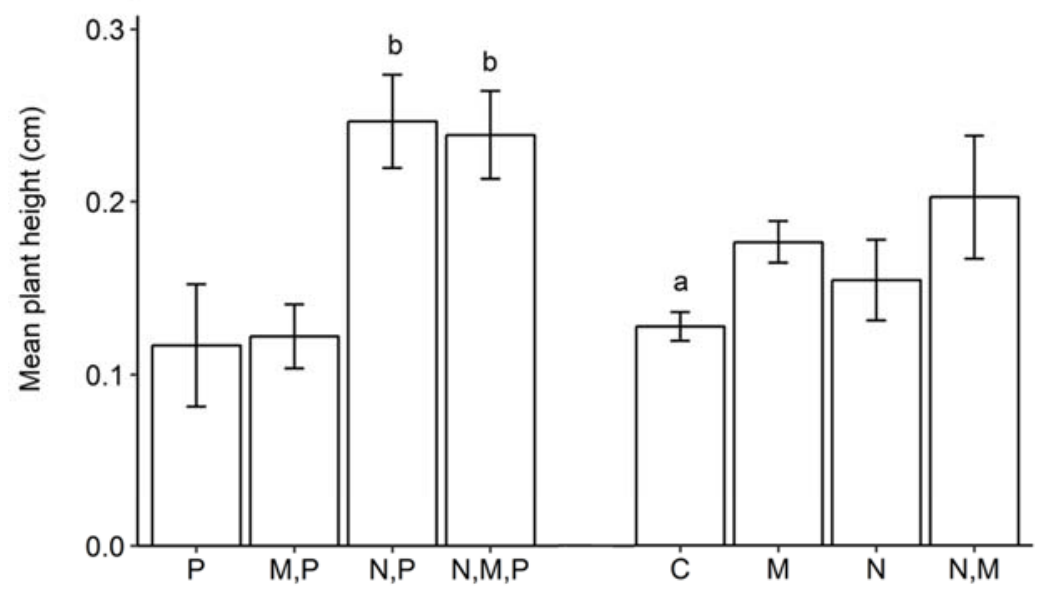

b) with P.polymyxa

without P.polymyxa

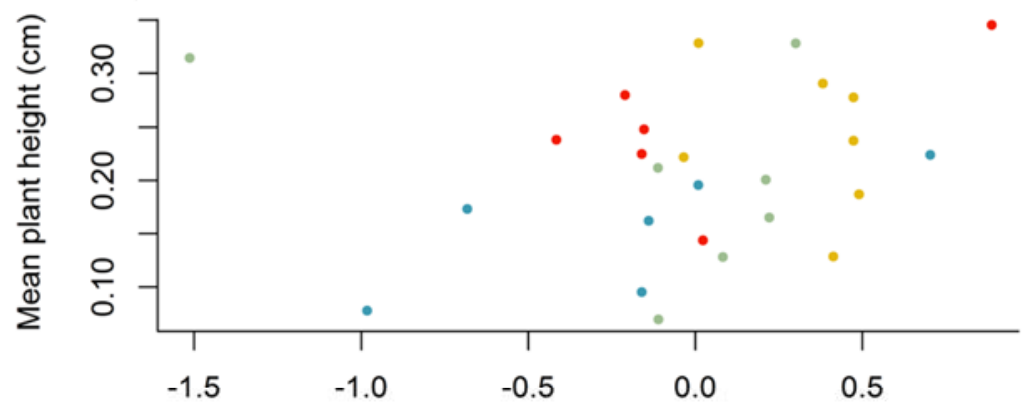

Loadinas for PCoA1

c)

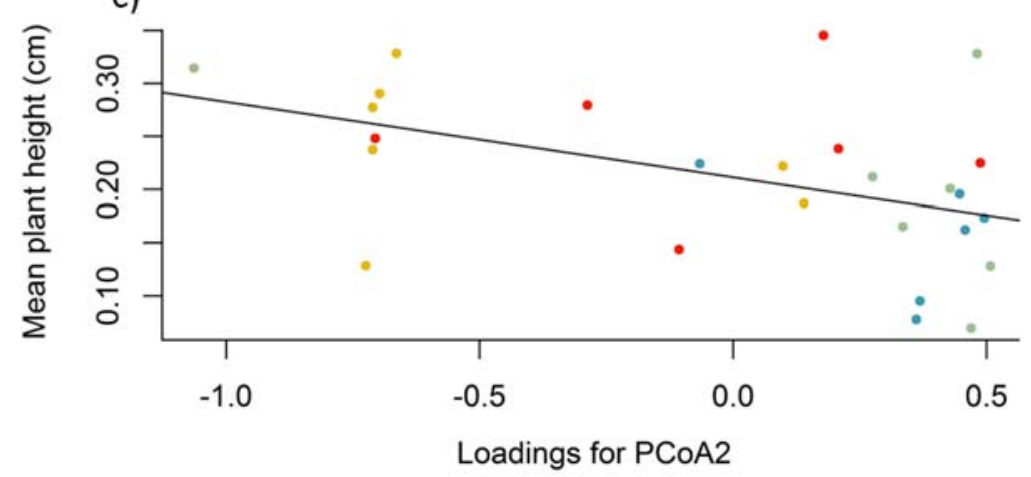




\section{With}

Paenibacillus polymyxa inoculation
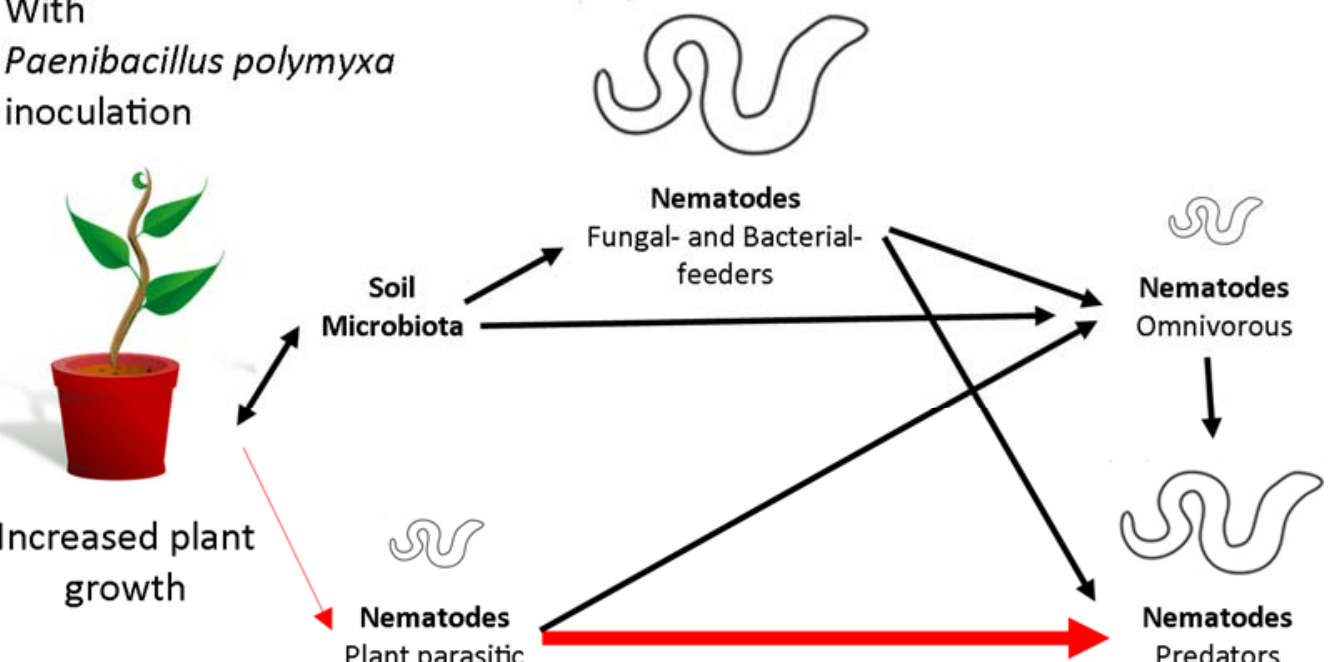

455

Paenibacillus polymyxa

456

457

458

459

460

461

462

463

464

465

466

467 
469 Table S1 Generalised least squares model output for the effect of treatment on predatory 470 nematode abundance

471

\begin{tabular}{cccccc}
\hline Treatment & $\begin{array}{c}\text { Mean } \\
\text { abundance }\end{array}$ & $\begin{array}{c}\text { Degrees of } \\
\text { freedom }\end{array}$ & Std.Error & $\begin{array}{c}\text { t-value (when } \\
\text { compared to } \\
\text { N) }\end{array}$ & $\begin{array}{c}\text { p-value (when } \\
\text { compared to } \\
\text { N) }\end{array}$ \\
\hline N & 9.24 & 26 & 9.24 & 1 & 0.33 \\
N,M & 4.91 & 26 & 4.90 & -0.45 & 0.66 \\
N,P & 18.38 & 26 & 13.10 & 0.70 & 0.49 \\
N,M,P & 191.98 & 26 & 60.25 & 3.03 & $<0.01$ \\
\hline
\end{tabular}

$\mathrm{N}=$ nematodes; $\mathrm{N}, \mathrm{M}=$ nematodes and below ground microbes $; \mathrm{N}, \mathrm{P}=$ nematode and $P$. polymyxa; $\mathrm{N}, \mathrm{M}, \mathrm{P}=$ nematodes, below ground microbes and $P$. polymyxa.

472

473

474 Table S2 Analysis results for testing the effect of treatment on plant growth

\begin{tabular}{cccccccc}
\hline Treatment & $\begin{array}{c}\text { Mean } \\
\text { plant } \\
\text { growth }\end{array}$ & Std.Error & $\begin{array}{c}\text { Degrees } \\
\text { of } \\
\text { freedom }\end{array}$ & $\begin{array}{c}\text { t-value } \\
\text { (when } \\
\text { compared } \\
\text { to C) }\end{array}$ & $\begin{array}{c}\text { p-value } \\
\text { (when } \\
\text { compared } \\
\text { to C) }\end{array}$ & $\begin{array}{c}\text { t-value } \\
\text { (when } \\
\text { compared } \\
\text { to N) }\end{array}$ & $\begin{array}{c}\text { p-value } \\
\text { (when } \\
\text { compared } \\
\text { to N) }\end{array}$ \\
\hline C & 0.13 & 0.01 & 46 & N/A & N/A & -0.74 & 1.00 \\
M & 0.18 & 0.01 & 46 & -1.41 & 0.85 & 0.61 & 0.99 \\
M,P & 0.12 & 0.02 & 46 & 0.16 & 1.00 & 0.90 & 0.99 \\
N & 0.16 & 0.02 & 46 & -0.74 & 0.99 & N/A & N/A \\
N,M & 0.20 & 0.04 & 46 & -2.15 & 0.40 & -1.32 & 0.89 \\
N,M,P & 0.24 & 0.03 & 46 & -3.19 & 0.048 & -2.32 & 0.305 \\
N,P & 0.25 & 0.03 & 46 & -3.28 & 0.04 & -2.45 & 0.24 \\
P & 0.12 & 0.04 & 46 & 0.31 & 1.00 & 1.04 & 0.97 \\
\hline
\end{tabular}

$\mathrm{C}=$ control; $\mathrm{M}=$ below ground microbes; $\mathrm{P}=P$. polymyxa; $\mathrm{M}, \mathrm{P}=$ below ground microbes and $P$. polymyxa; $\mathrm{N}=$ nematodes; $\mathrm{N}, \mathrm{M}=$ nematode and below ground microbes; $\mathrm{N}, \mathrm{P}=$ nematodes and $P$. polymyxa; $\mathrm{N}, \mathrm{P}, \mathrm{M}=$ nematodes, below ground microbes and $P$. polymyxa. 